\title{
COVID-19: An Urgent Call for Coordinated, Trusted Sources to Tell Everyone What They Need to Know and Do
}

\author{
Scott C. Ratzan, MD, MPA, MA, CUNY Graduate School of Public Health and Health \\ Policy; Lawrence O. Gostin, JD, Georgetown University; Najmedin Meshkati, PhD, \\ CPE, University of Southern California; Kenneth Rabin, PhD, Journal of Health \\ Communication: International Perspectives, and Ruth M. Parker, MD, Emory \\ University
}

March 5, 2020

Disclaimer: The views expressed in this paper are those of the authors and not necessarily of the authors' organizations, the National Academy of Medicine (NAM), or the National Academies of Sciences, Engineering, and Medicine (the National Academies). This paper is intended to inform and stimulate discussion. It is not a report of the NAM or the National Academies.

Since 1995, the global community has experienced six outbreaks that the World Health Organization (WHO), as authorized in a 2005 revision of the International Health Regulations (IHR), designated as a Public Health Emergency of International Concern (PHEIC): H1N1 Influenza, polio, Ebola in West Africa and in the Democratic Republic of Congo, Zika, and now a novel coronavirus, which WHO officially termed SARS-CoV-2. SARS-CoV-2 is the virus responsible for the disease state termed COVID-19. Two other novel coronaviruses, severe acute respiratory syndrome (SARS) and Middle East respiratory syndrome (MERS), also spread internationally. SARS occurred before the major IHR revision in 2005 and thus was not designated a PHEIC. MERS arose on the Saudi peninsula after the IHR revision, but WHO never officially designated it a PHEIC, even though it spread internationally, including a major outbreak in South Korea.

PHEIC is not a color- or numeric-coded system of alert levels, but is strictly a technical description designed to support coordination among the 196 states that are parties to the IHR-coordination which has so far proven difficult to achieve in the case of COVID-19.

\section{COVID-19 Response}

It is believed that the virus responsible for COVID-19 originated from an animal found in an open-air food market in Wuhan, Hubei Province, China. Many possibilities have been discussed since the virus emerged, but the original reservoir species (initially thought to be a species of bat) has not been confirmed. Whether directly or through an intermediary animal, the virus "jumped" from this initial reservoir species to humans. After this initial transmission, the outbreak appears to be sustained through relatively efficient human-tohuman transmission. Fortunately, from available data, the fatality rate appears relatively low compared with SARS and MERS.

Wuhan is central China's transportation hub, and soon after the outbreak began, some 5 million travelers left the region for other locations in mainland China and global destinations-many traveling in anticipation of the Lunar New Year. As the outbreak progressed, the Chinese government took the unprecedented step of quarantining the 50 million inhabitants of Wuhan and the wider Hubei province. Further complicating the global response to the pandemic, a suddenly symptomatic Chinese passenger caused a Mediterranean cruise ship, Costa Smeralda, with 6,000 passengers on board to be placed under quarantine in Italian waters. A second cruise ship, Diamond Princess, was also quarantined off Yokohama, Japan, after a passenger became symptomatic. Almost all airline flights to and from China have been grounded (as of 
the publication of this Commentary), and this extreme disruption of both traffic and commerce to and from the world's second largest economy has had a growing and potential seismic effect on global production, supply chains, and financial markets.

On January 30, 2020, WHO declared the outbreak of COVID-19 a PHEIC [1]. A day later, the U.S. Department of Health and Human Services (HHS) declared COVID-19 a national public health emergency [2]. The U.S. Centers for Disease Control and Prevention (CDC) implemented enhanced border screening and a 2-week quarantine of passengers traveling to the United States from the outbreak's epicenter, including evacuees from Wuhan; the U.S. Department of State banned foreign nationals who had recently been to Hubei province from entering the United States; and U.S. airlines and other foreign carriers indefinitely suspended flights to China.

COVID-19 is an especially mysterious PHEIC, and in today's 24-hour media environment, is covered continually and in real time. All of the developments above were broadcast globally on television, radio, newspapers, and news sites as they occurred, with sites sometimes reporting conflicting information simultaneously. Social media outlets were also active participants, and quickly became home to ample misinformation-so much so that Facebook vowed to block all but official health pronouncements on COVID-19 posted to the site, and Pinterest made all of its searches for coronavirus connect to posts created and approved by WHO, the search displaying a banner stating that all of the pins that appear are from verified medical sources.

\section{COVID-19 Communication Challenges}

The rapid escalation of the virus has been associated with confusing and sometimes contradictory communication about its spread and what individuals need to know and do about COVID-19. As information becomes available at unpredictable times and in unpredictable ways, it has been challenging to report on the status of the outbreak in a manner that is always consistent with the reporting that has come before.

These sometimes contradictory messages are confusing to the general public and may undermine both the public health response and public trust in official information sources. Increasingly, people may wonder how transparent, honest, and up to date the information they are receiving is-and whether they should believe it. The authors of this Commentary agree that a responsible public health and health communication response to this pandemic is critical, but wonder if it can be achieved if the public does not believe what they are being told.

\section{Need for Reliable and Effective Communica- tion}

COVID-19 is a test of the global health polity's credibility in addressing a legitimate public health threat with an unknown trajectory. This sort of an emergent threat requires government, media, technology platforms, and the private sector to step up. A responsible communication response to the pandemic requires cooperation and coordination among all sectors. The public needs reliable and actionable information to help them understand their risk of exposure as they go about their lives in apartment complexes, airports, schools, supermarkets, or at health clinics. The public needs clarity and transparency about travel bans, quarantines, personal protection efforts, and social distancing (e.g., closing mass transit, closing schools, or cancelling sporting events). Moreover, the public needs the assurance that as more is learned about this emerging infection, the information they get from trusted sources reflects both accurately and clearly what the health care establishment does and does not know about COVID-19. Indeed, there are data voids and the public health community does not have all of the evidence needed to reliably predict the trajectory of this infection. Unfortunately, this uncertainty creates a ripe environment for both fear and misinformation.

Policy makers, health workers, and the business community need to agree on what information to communicate, as well as the channels of communication and specific, credible spokespeople they use. Messages must be updated as soon as new information is validated by public health authorities, and where there is little new to report, the opportunity should be utilized to reiterate basic infection control information consistently and often (e.g.: "Protect yourself and your family. Wash your hands frequently. Avoid exposure to people who have flu-like symptoms. Stay up to date with all vaccinations").

Health communication professionals have learned valuable lessons from previous public health threats, such as HIV/AIDS, "mad cow disease", anthrax, H1N1, SARS, and MERS, and these lessons should also be applied to COVID-19. One of the most important of these lessons is the use of a trusted, known public health source, such as the U.S. Surgeon General or others, to be the "face" and "voice" of evidence-based, up-to-date, trustworthy information that everyone can obtain, process, and understand in order to make appropri- 
ate health decisions. A single strong voice at the federal level can allow state, county, city, and local health departments to assume their roles as locally-trusted sources of the best available information for the public to access, understand, and use to protect themselves and their families. Health communication professionals must continue to emphasize the importance of message repetition, suggesting a potential role for the U.S. Ad Council, the creators of Smokey Bear. The public health community must not stop at issuing one set of messages one time.

Public health professionals know that the public wants this type of trusted leadership. A national Emerson College poll conducted in February 2020 showed that half of the American public believes communication from the U.S. Surgeon General is a needed and appropriate action to address the threat of coronavirus. [5]

\section{Systems Thinking and Ways to Improve Com- munication}

Coordinated and reliable health communication is required on a global level, as COVID-19 should not threaten livelihoods and undermine businesses without a bona fide reason. Those in health care leadership positions should work to strengthen the communication readiness and response of international institutions, such as WHO, as well as provide government, medical, and community leaders with up-to-date, health literate information and communication strategies that inform individual response and beliefs about the disease.

Being prepared with a plan and being proactive are essential to the prevention, mitigation, and management of risk and adverse consequences of any disaster. First responders and clinicians should receive equal and adequate attention when considering communication strategies, as well as researchers who work at data and wet laboratories on SARS-CoV-2. Front-line personnel, including first responders and clinicians, always constitute both the first (detection) and last (treatment) layer of defense against any outbreak anywhere. As Dr. Tedros Adhanom Ghebreyesus, WHO director-general said, "This [understanding of the role and communication abilities of front-line health workers] is a critical piece of information, because health workers are the glue that holds the health system and outbreak response together" [3]. The physical and cognitive capabilities of these personnel, or their human performance factors in the detection, spread, and containment of coronavirus, are of paramount importance. [4]
The authors of this Commentary suggest that a leading governmental medical spokesperson, such as the U.S. Surgeon General or others, should be tasked to create and lead a credible, public-private, interdisciplinary "COVID-19 News Bureau" to inform the United States and serve as an international resource in times of emerging global health threats. Such a bureau could forge long-term relationships with both traditional and social media to deliver sustained, up-to-date, evidencebased, health literate communication and serve as a central resource for compelling, scientifically sound information, medical strategies, personal protection measures, electronic resources, and even frugal innovation for use among multiple parties (including blogs, checklists, mHealth alerts).

\section{Conclusion}

History tells us that an informed, activated population is vital to protecting the public health. To make this happen, the global community needs informed and active public policy leadership that employs strategically coordinated health communication and outreach. The public needs and wants to be able to believe and follow evidence-based guidance from trusted sources. Sound health communication will serve the public well as public health professionals manage the national response to COVID-19 and strengthen the health information infrastructure for when the next novel infection strikes.

\section{References}

1. WHO (World Health Organization). 2020. Statement on the second meeting of the International Health Regulations (2005) Emergency Committee regarding the outbreak of novel coronavirus (2019-nCoV). Available at: https://www.who.int/news-room/ detail/30-01-2020-statement-on-the-secondmeeting-of-the-international-health-regulations(2005)-emergency-committee-regarding-theoutbreak-of-novel-coronavirus-(2019-ncov). (accessed February 20, 2020).

2. HHS (U.S. Department of Health and Human Services). 2020. Secretary Azar declares public health emergency for United States for 2019 novel coronavirus. Available at: https://www.hhs.gov/about/ news/2020/01/31/secretary-azar-declares-publichealth-emergency-us-2019-novel-coronavirus. html (accessed February 20, 2020).

3. World Health Organization: Coronavirus must generate "solidarity not stigma." 2020 (February 14). UN News. Available at: https://news.un.org/en/sto- 


\section{COMMENTARY}

ry/2020/02/1057431 (accessed February 24, 2020).

4. NRC (National Research Council). 1999. Strategies to protect the health of U.S. forces: Force protection and decontamination. Washington, DC: National Academy Press. https://doi.org/10.17226/9717.

5. Emerson Polling. 2020. February National Poll: Sanders Takes the Lead for Democratic Nomination, Bloomberg on the Rise. Available at: http://emersonpolling.com/2020/02/19/february-nationalpoll-sanders-takes-the-lead-for-democratic-nomination-bloomberg-on-the-rise/ (accessed March 2, 2020).

\section{DOI}

https://doi.org/10.31478/202003a

\section{Suggested Citation}

Ratzan, S., L. Gostin, N. Meshkati, K. Rabin, and R. Parker. 2020. COVID-19: An Urgent Call for Coordinated, Trusted Sources to Tell Everyone What They Need to Know and Do. NAM Perspectives. Commentary, National Academy of Medicine, Washington, DC. https:// doi.org/10.31478/202003a

\section{Author Information}

Scott C. Ratzan is Distinguished Lecturer at CUNY Graduate School of Public Health and Health Policy and Editor-in-Chief, Journal of Health Communication: International Perspectives. Lawrence O. Gostin is Professor of Global Health Law, Georgetown University and a member of the National Academy of Medicine. Najmedin Meshkati is Professor of Civil/ Environmental Engineering, Industrial \& Systems Engineering and International Relations, University of Southern California. Kenneth Rabin is Special Projects Editor, Journal of Health Communication: International Perspectives. Ruth M. Parker is Professor of Medicine, Pediatrics, and Public Health and Senior Fellow, Center for Ethics, Emory University.

Scott Ratzan and Lawrence Gostin are members of the Board on Global Health and Najmedin Meshkati is on the Board on Human-Systems Integration at the National Academies of Sciences, Engineering, and Medicine.

\section{Acknowledgments}

The authors would like to thank Lauren Rauh, Research Assistant at CUNY School of Public Health, for editing and coordination of the contributors.

\section{Conflict-of-Interest Disclosures}

None to disclose.

\section{Correspondence}

Questions or comments should be directed to Scott Ratzan at Scott.Ratzan@sph.cuny.edu.

\section{Disclaimer}

The views expressed in this paper are those of the authors and not necessarily of the authors' organizations, the National Academy of Medicine (NAM), or the National Academies of Sciences, Engineering, and Medicine (the National Academies). The paper is intended to help inform and stimulate discussion. It is not a report of the NAM or the National Academies. Copyright by the National Academy of Sciences. All rights reserved. 